\title{
Chemiese aanpassing van ZIF-67 nanodeeltjies vir toepassing as geneesmiddeldraers
}

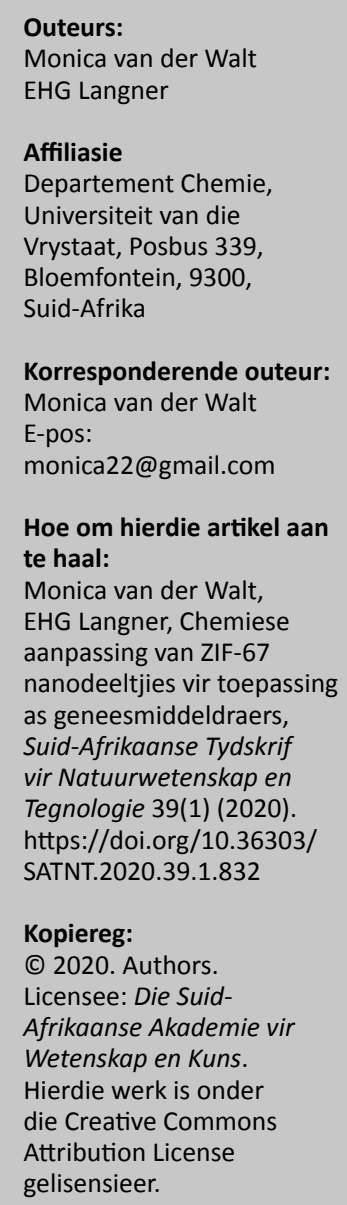

Chemical adaptation of ZIF-67 nanoparticles for application as drug carriers: ZIF-67 nanoparticles were synthesised under ambient conditions and characterised by PXRD, IR, TEM, ASAP and TGA. During Solvent-assisted ligand exchange (SALE) on ZIF-67, its 2-methylimidazolate linkers were partially replaced with 2-aminobenzimidazolate linkers. During SALE, amino-active sites were introduced, to which ferrocenecarboxylic acid, a potential anticancer drug, was attached.

Metaalorganiese raamwerke (MOFs) is mikroporeuse kristallynstrukture wat uit oorgangsmetaalione bestaan wat onderling deur organiese ligande verbind is. Zeolitiese imidasolaat raamwerke (ZIFs) is MOF-materiale waarvan die oorgangsmetaalnodes onderling deur middel van imidasolaat ligande verbind is. Die topologie van die ZIF-materiale is soortgelyk aan dié van zeoliete. ZIF-materiale is oor die algemeen in 'n hoë mate termies en chemies stabiel. Die uiterste stabiliteit van ZIF-materiale in lug en vog maak hulle geskik vir toepassings in gasberging, katalise en as geneesmiddeldraers. Hierdie navorsingsprojek fokus op die biomediese toepassing van ZIF-67 na die post-sintetiese aanpassing daarvan met 2-aminobensimidasool en ferroseenkarboksielsuur. Verskeie ferroseenderivate is bekend vir hulle antineoplastiese eienskappe. ZIF-67 sal dus optree as 'n geneesmiddeldraer. Een van die mees gesogte eienskappe van geneesmiddeldraers is $\mathrm{pH}$-sensitiwiteit, aangesien die $\mathrm{pH}$ van tumorweefsel effens suurder ( $\mathrm{pH}$ 5.5-6.0) as die $\mathrm{pH}$ van normale weefsel ( $\mathrm{pH} 7.4)$ is. Aangesien ZIF-67 in ' $n$ suurmedium ontbind, sal dit enige geankerde of ingeslote geneesmiddel kan vrystel sodra dit tumorweefsel binnedring. Die slegte newe-effekte van baie teenkankermiddels sal dus dramaties verminder word indien hierdie middels slegs in kankergewasse vrygestel word.

ZIF-67nanodeeltjies is onder omgewingstoestandegesintetiseer deur kobaltnitraatheksahidraat en 2-metielimidasool in water (6 uur) of metanol (1 uur) te meng by kamertemperatuur. Die produkte is gekarakteriseer met PXRD (poeier X-straaldiffraksie), IR (infrarooi-spektroskopie), TEM (transmissie-elektronmikroskopie), ASAP (versnelde oppervlakarea en porositeitsanalise) en TGA (termogravimetriese analise). Liganduitruiling in ' $\mathrm{n}$ metanoloplossing (SALE) is uitgevoer op gesuspendeerde ZIF-67 nanodeeltjies in 'n outoklaaf by $60^{\circ} \mathrm{C}$ oor 72 uur. Die 2-metielimidasolaat ligande van ZIF-67 is gedeeltelik vervang met 2-aminobensimidasolaat ligande. Die persentasie liganduitruiling van ongeveer $10 \%$ is met ${ }^{1} \mathrm{H} \mathrm{KMR}$ na vertering in 'n $\mathrm{D}_{2} \mathrm{SO}_{4}$ aangesuurde $\mathrm{D}_{2} \mathrm{O}$-oplossing bepaal. Die doel van liganduitruiling was die daarstelling van amino-aktiewe sentra waaraan ferroseenkarboksielsuur, 'n potensiële teenkankermiddel, geheg is. Ferroseenkarboksielsuur is in twee stappe gesintetiseer vanaf ferroseen via ferroseenkarboksaldehied en gekarakteriseer met ${ }^{1} \mathrm{H}$ KMR en IR-spektroskopie. Ferroseenkarboksielsuur is daarna kovalent geanker op die amiengefunksionaliseerde ZIF-67 nanodeeltjies en gekarakteriseer met IR-spektroskopie, ${ }^{1} \mathrm{H}$ KMR, ${ }^{13} \mathrm{C}$ KMR, TEM en PXRD. Die verhouding tussen die strukturele kobalt en die ferrosenielgebonde yster in die eindproduk, is bepaal met X-straal foto-elektronspektroskopie (XPS) en induksiegekoppelde plasma optiese uitstralingspektrometrie (ICP-OES).
Nota: 'n Seleksie van referaatopsommings: Studentesimposium in die Natuurwetenskappe, 31 Oktober - 1 November 2019 , Universiteit van die Vrystaat. Reëlingskomitee: Prof Rudi Pretorius (Departement Geografie, Universiteit van Suid-Afrika); Dr Hertzog Bisset (Suid-Afrikaanse Kernenergie-korporasie; Dr Ernie Langner (Departement Chemie, Universiteit van die Vrystaat) en Dr Wynand Nel (Departement Rekenaarwetenskap en Informatika, Universiteit van die Vrystaat). 